\title{
Estimation of stature from facial indices among Iranian medical students
}

\author{
Soheila Madadi, Fatemeh Tahmasebi, Maryam Khanehzad, Shokofeh Kazemzadeh, and \\ Gholamreza Hassanzadeh*
}

\author{
Department of Anatomy, School of Medicine, Tehran University of Medical Sciences, Tehran, Iran. \\ *Correspondence to Gholamreza Hassanzadeh (email: hassanzadeh@tums.ac.ir). \\ (Submitted: 26 October 2018 - Revised version received: 17 November 2018 - Accepted: 27 January 2019 - Published online: 26 April 2019)
}

\begin{abstract}
Objective Anthropometric data, particularly nasofacial dimensions, is important in sex determination, forensic medicine and plastic surgery. The aim of this study is to assess the facial indices, to classify the type of face and to determine the relation between stature and facial height and facial width among Iranian medical students.

Methods This study was done on 200 medical students (100 males and 100 females), in the age range of 18-30 years. Stature, facial height and facial width were measured by using a standard spreading caliper and facial index calculated for determination of facial type. The linear regression used for examining the relationship between stature and facial length and facial width.

Results The result of study showed that the mean and standard deviation of the facial index of males and female students were $87.53 \pm 8.81$ and $89.25 \pm 10.09$, respectively. The facial index did not have statistically significant difference between two groups $(P=0.202)$. According to the results, the dominant type of facial shape in male students was mesoprosopic and in female students were europrosopic. There was a correlation between stature and facial height $(r=0.27, P=0.000)$ and facial width $(r=0.54, P=0.000)$.

Conclusion The data of this study can be beneficial in face reconstruction, clinical diagnosis and forensics applications.

Keywords Facial height, facial width, facial index, stature
\end{abstract}

\section{Introduction}

Craniofacial measurement is an important part of anthropology and medicine that determine the morphological features of the face and head. ${ }^{1}$ Shape of face is affected by many agents, for instance, gender, race and ethnicity, nutritional, climate, socio-economic, and genetic factors. ${ }^{1,2}$ The determination of facial parameters is useful in plastic surgery, forensics applications, head and face reconstruction, oral and maxillofacial surgery, orthodontics, clinical diagnosis and treatment planning. ${ }^{3-5}$

According to craniofacial measurements, shape of faces are classified into five anatomical types that include: hypereuryprosopic, euryprosopic, mesoprosopic, leptoprosopic and hyperleptoprosopic. $^{6}$ By using facial measurements for example facial height, facial width and facial index is beneficial to identify the genetically and acquired defects. Facial type can be an effective element to increase capability of obstructive sleep apnea for instance a person with euryproscopic facial type prefers the nasal breathing mode. ${ }^{7,8}$ Comparing the facial index differences among parents, offspring and sibling may be a sign for genetic transition. ${ }^{9}$ In addition, different studies showed a relation between the stature with body parts measurement, but there is few studies in this field among Iranian population. ${ }^{10-12}$ These kinds of studies might be beneficial for stature estimation in growth defects and skeletal dysplasia cases. ${ }^{13}$

The aim of this study is to determine the facial indices and to classify the facial type in Iranian medical students. And also this study assessed the relationship between facial width and facial height with the stature in Iranian medical students.

\section{Materials and Methods}

This study was carried out on 200 medical students of Tehran University of Medical Sciences, Tehran, Iran (100 males and 100 females), with age range of 18-30 years with normal craniofacial configurations.
The students were sitting on the chair, and their head were in the anatomical position.

Facial height and facial width were measured by using a standard spreading caliper with scale. The measurement of facial height was taken the distance between nasion (n) and gnathion (gn). And the measurement of face width was taken the distance between zygion (zy) of right and left side.

To calculate facial index the following formula was used:

$$
\text { Facial index }=\frac{\text { Facial length }}{\text { Facial width }} \times 100
$$

The anatomical landmarks used in measuring of the parameters were defined as follows:

Nasion (n): the point on the nasal root in the midpoint of the nasofrontal suture.

Gnathion (gn): the lowest point on the lower border of the mandible in the midline.

Zygion (zy): it is the most lateral point on the zygomatic arch.

According to facial index, face shapes were classified to five categories that include (Banister's classification) (14):

1. Hypereuryprosopic (very broad, short face): facial index $<79.9$.

2. Euryprosopic (broad, short face): facial index 80-84.9.

3. Mesoprosopic (average, round face): facial index 85-89.9.

4. Leptoprosopic (long, narrow face): facial index 90-94.9.

5. Hyperleptoprosopic (very long, narrow face): facial index $>95$.

The stature (standing height) of subjects was measured as distance between the vertex and the heel in centimeters. Individuals stood barefoot on a flat surface and their head was stated in the Frankfort horizontal plane. ${ }^{15}$ The data were analyzed by SPSS 16 software and expressed as mean \pm SEM. Independent-samples $t$-test was used for comparison of the means of the anthropometric measurements. The relationship 
between quantitative data was assessed by Pearson's correlation coefficient and linear regression was used to determine the relation between stature with facial length and facial width. Statistical significance was considered to be $P \leq 0.05$.

\section{Results}

In this study, the facial height was assessed and the results revealed that the mean and standard deviation facial height of male and female students were $12.32 \pm 1.06$ and $11.57 \pm 1.12$ $\mathrm{cm}$, respectively. There was a significant difference in the facial height of students between two sex groups $(P=0.0001$, Table 1$)$. According to Table 1, mean and standard deviation facial width of male and female students were $14.11 \pm 0.76$ and 13.00 $\pm 0.64 \mathrm{~cm}$, respectively. There was a significant difference in the facial width of cases between two sex groups $(P=0.0001)$. The obtained results showed that mean and standard deviation of the facial index of male and female students were $87.53 \pm$ 8.81 and $89.25 \pm 10.09$ respectively. Also facial index was not statistically significant difference between male and female students $(P=0.202$, Table 1$)$.

According to the results, the common face shape for male and female students were mesoprosopic (round face) and europrosopic (broad face), which was 33\% and 36\% for male and female students, respectively. The second most dominant face shape for males was europrosopic that was $25 \%$ but for females it was mesoprosopic and leptoprosopic (long face) that each of them was $20 \%$. The rare face shape was hypereuryprosopic (very broad face) for both groups, which was $11 \%$ and $8 \%$ for males and females, respectively (Table 2, Figs. 1 and 2).

Mean and standard deviation stature of male and female students were $177.202 \pm 6.04$ and $161.94 \pm 6.17 \mathrm{~cm}$, respectively. There was a significant difference in the stature of students between two groups $(P=0.000$, Table 3$)$.

Also, there was a correlation between stature with facial height and facial width that was statistically significant. Pearson

Table 1. Comparison of facial height, facial width and facial index in male and female students

\begin{tabular}{lcccc}
\hline \multirow{2}{*}{ Parameters } & \multicolumn{2}{c}{$\boldsymbol{N}$} & \multicolumn{2}{c}{ Mean \pm SD } \\
\cline { 2 - 5 } & Male & Female & Male & Female \\
\hline Facial height & 100 & 100 & $12.32 \pm 1.06$ & $11.57 \pm 1.12$ \\
Facial width & 100 & 100 & $14.11 \pm 0.76$ & $13.00 \pm 0.64$ \\
Facial index & 100 & 100 & $87.53 \pm 8.81$ & $89.25 \pm 10.09$ \\
\hline
\end{tabular}

SD: standard deviation; $N$ : number of samples.

Table 2. Distribution of facial type in male and female students

\begin{tabular}{lccc}
\hline Face shape & $\begin{array}{c}\text { Range of facial } \\
\text { index }\end{array}$ & Male & Female \\
\hline $\begin{array}{l}\text { (1) Hypereuryprosopic (very } \\
\text { broad face) }\end{array}$ & $<79.9$ & 11 & 8 \\
$\begin{array}{l}\text { (2) Europrosopic (broad face) } \\
\text { (3) Mesoprosopic (round face) }\end{array}$ & $80-84.9$ & 25 & 36 \\
(4) Leptoprosopic (long face) & $95-89.9$ & 33 & 20 \\
$\begin{array}{l}\text { (5) Hyperleptoprosopic (very } \\
\text { long face) }\end{array}$ & $>95$ & 17 & 20 \\
\hline
\end{tabular}

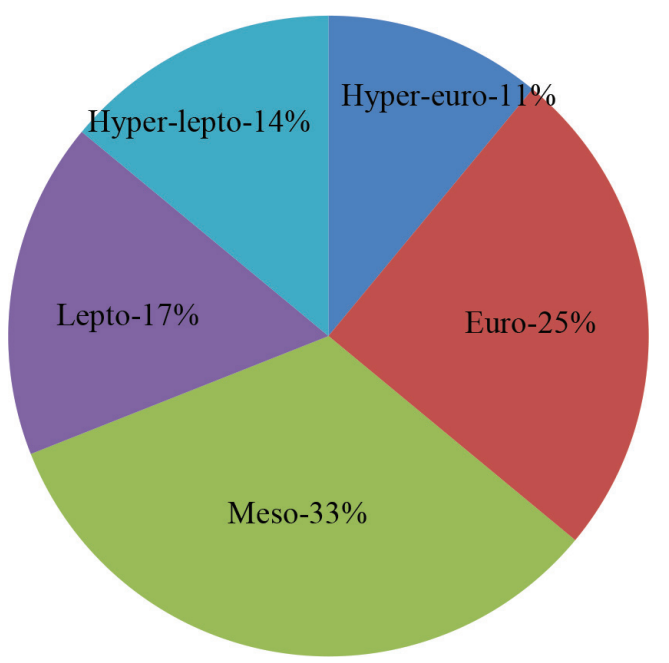

Fig. 1 Morphological variation of facial index in male students.

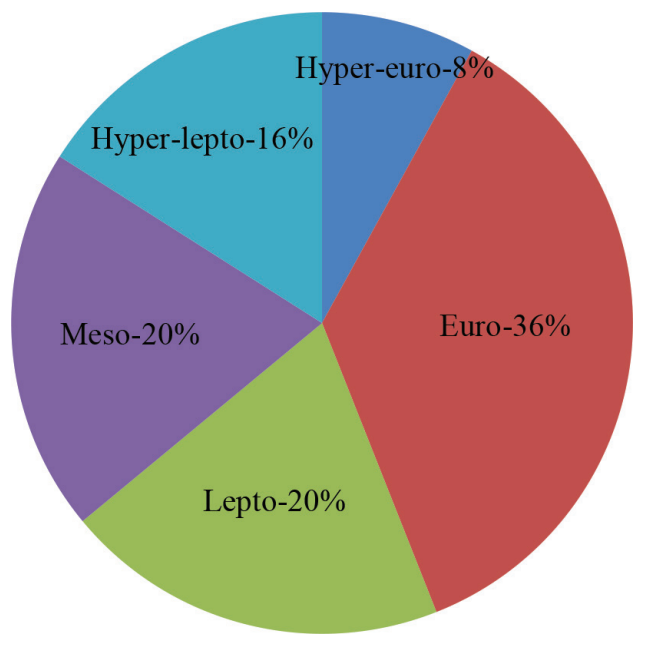

Fig. 2 Morphological variation of facial index in female students.

Table 3. Comparison of stature in male and female students

\begin{tabular}{lcc}
\hline Groups & $\boldsymbol{N}$ & Mean \pm S.D \\
\hline Male & 100 & $177.202 \pm 6.04$ \\
Female & 100 & $161.94 \pm 6.17$ \\
\hline
\end{tabular}

SD: standard deviation; N: number of samples.

correlation $(r)$ for stature with facial height and facial width was 0.27 and 0.54 , respectively $(P=0.000$, Table 4$)$. The correlation between stature with facial height and width are shown in Scatter graphs (Fig. 3).

Linear regression analysis showed a relation between stature with facial height and facial width in all cases. According to the results, the facial width can predict the stature better than facial height (Table 5).

\section{Discussion}

In this study the facial index of students of Tehran University of Medical Sciences in the range of 18-30 years old evaluated. Facial index calculated by ratio of facial height to facial width and multiplied by 100 . The result of study showed that the mean 
Table 4. Pearson correlation (r) between stature with facial height and facial width

\begin{tabular}{lcl}
\hline Variable & Pearson correlation $(\boldsymbol{r})$ & $\boldsymbol{P}$ \\
\hline Facial height & 0.27 & 0 \\
Facial width & 0.54 & 0 \\
\hline
\end{tabular}
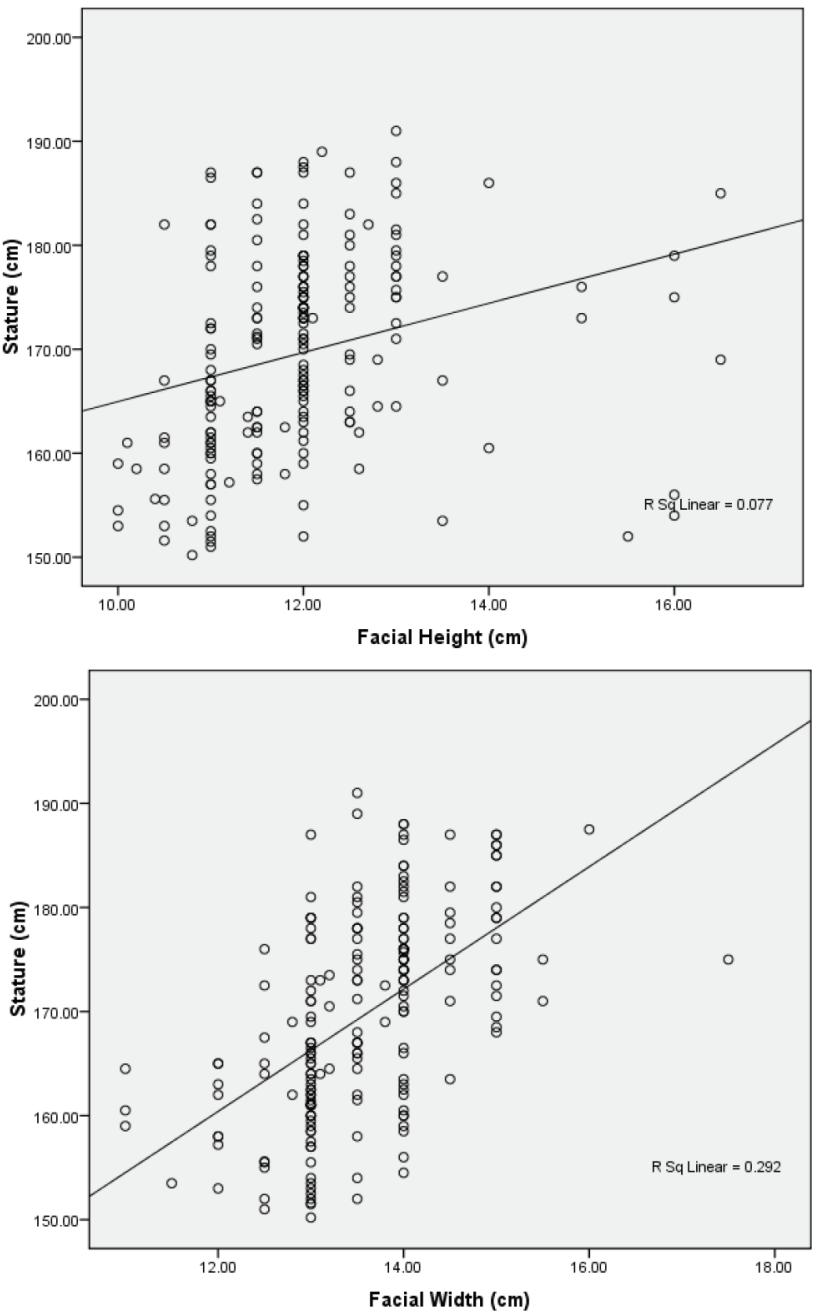

Fig. 3 Correlation between stature $(\mathrm{cm})$ and facial height $(\mathrm{cm})$ and facial width $(\mathrm{cm})$.

Table 5. Linear regression for estimation of stature from facial height and facial width

\begin{tabular}{lccccc}
\hline Regression equation & \multicolumn{2}{c}{ SEE } & \multirow{2}{*}{$\boldsymbol{R}^{2}$} & $\boldsymbol{P}$ \\
\cline { 2 - 3 } & FW & FH & & \\
\hline$S=141.33+2.36(\mathrm{FH})$ & 0.58 & - & 0.07 & 0 \\
$\mathrm{~S}=89.85+5.87(\mathrm{FW})$ & - & 0.65 & 0.29 & 0 \\
$\mathrm{~S}=77.01+1.51(\mathrm{FH})+5.49(\mathrm{FW})$ & 0.508 & 0.65 & 0.32 & 0 \\
\hline
\end{tabular}

S: stature, FH: facial height, FW: facial width, SEE: standard error of the estimate, $R^{2}$ : coefficient of determination.

facial index of male and female cases were 87.53 and 89.25 , respectively. It was not statistically significant difference between two gender $(P=0.202)$. The involved students came from various ethnic and geography. And biological, geographical, race, gender and nutritional condition were effective factors on the facial indices and stature. ${ }^{16}$ Our findings were similar to Shetti et al.s study. They showed that mean facial index for males was 87.19 and mean facial index for females was 86.75 in Indian students with a statistically significant difference between two groups $(P=0.018) .{ }^{17}$ Kumar et al. reported the mean facial index among adult Haryanvi Banias was 86.09 in males and 84.84 in females and the dominant face type in males and females were mesoprosopic and europrosopic, respectively. These findings are similar to our research. ${ }^{18}$ According to Wai et al.s study, the mean facial index in male and female Malay young adults were 87.04 and 90.59 , respectively, and the face form of males were mesoprosopic and of females were leptoprosopic, respectively. In Chinese young adults, the facial index was 85.90 in male cases and 85.40 in female cases with a mesoprosopic face type for both genders. The mean facial index in male and female Indian young adults was 92.14 and 92.99 , respectively, with leptoprosopic face type for both genders. ${ }^{19}$

Sharma et al's study revealed the mean facial index of Nepalese students for males and females as 87.20 and 86.81, respectively. The difference between two groups was not statistically significant $(P=0.553)$. The most common face shape between male Nepalese students was euryprosopic and females was mesoprosopic, which is completely contrary to our study, that the dominant type of facial shape for males students was mesoprosopic and females students was europrosopic. ${ }^{20}$ Also, our findings differed from the study of Kurnia et al. ${ }^{7}$ that reported the dominant face type was leptoprosopic type in male and mesoprosopic type in female among Chinese in Indonesia. Azizi et al. ${ }^{21}$ showed the most common facial type was hyperleptoprosopic type among males and females in Qazvin, Iran. The study of Jahanshahi et al. showed that the face form of the native Fars and Turkman males were mesoprosopic. And the face form of the native Fars and Turkman females were euryprosopic, which is similar to the results of this study. The least common facial shape in the native Fars males was hyperleptoprosopic and hypereuryprosopic and in females were hyperleptoprosopic. The least common facial shape in the Turkman males and females were hypereuryprosopic and leptoprosopic, respectively. In this study, the rare type of face form was hypereuryprosopic for both sexes, which in male students is similar to the findings of Jahanshahi et al's study in Fars and Turkman males. Also, the mean facial index of Fars males and females were 88.22 and 84.48 , respectively. The mean facial index of Turkman males and females were 87.25 and 81.48 , respectively that is closely similar to the results of this study. ${ }^{22}$ The results of this study resembled with Salve et al. ${ }^{23}$ study that showed the dominant face type in Andhra region males and females were mesoprosopic and euryproscopic, respectively.

According to gained results the dominant face shape in females are euryprosopic, while in males are mesoprosopic. It indicates that female students have a rather broad face than male students. This study that had been carried out on 200 students, presented the anthropometrical differences between students of Tehran University of Medical Sciences. ${ }^{18}$ Generally, types of face shape are affected by geographical and ethnical factors and show broad, round or long faces in every population. ${ }^{22}$ The facial indices assessment can be used for sex determination, forensics medicine, and facial plastic surgeries. And more researches are required in a larger sample between Iranian population to apply in the medical and surgical purposes. ${ }^{19}$ 
In this study, stature was compared with facial height and facial width of the students and the results of study showed a correlation between them.

The correlation coefficient $(r)$ between stature and facial height and facial width was 0.27 and 0.54 , respectively. The linear regression equation showed that stature is estimated by facial height and facial width.

Linear regression analysis showed a poor relation between stature and facial height $(S=141.33+2.36 \times$ Facial height $\left.(\mathrm{cm}), R^{2}=0.07, \mathrm{SEE}=0.58\right)$ and a moderate relation between stature and facial width $(\mathrm{S}=89.85+5.87 \times$ Facial width $(\mathrm{cm})$, $R^{2}=0.29$, SEE $=0.65$ ).

In several studies, the stature estimated from body parts including cephalofacial, upper and lower limb measurements such as forearm length, and foot length. ${ }^{24-28}$

Krishan et al. showed the correlation between stature with facial height $(r=0.34)$ and facial width $(r=0.46)$ in North Indian population. The result of their study is similar to this study which shows facial width is more reliable for stature estimation than facial height. ${ }^{29}$

Sahni et al. used facial height for prediction of stature in northwest Indians and its correlation coefficient $(r)$ was 0.21 in males and 0.18 in females. ${ }^{30}$

Agnihotri et al's study showed a correlation between stature with facial height ( $r=0.32$ in males and $r=0.16$ in females) and facial width ( $r=0.17$ in males and $r=0.27$ in females). Their result showed that facial height is a more suitable parameter in males than facial width for estimation of stature while in females it is vice versa. ${ }^{31}$

Wankhede et al. reported a relation between stature with facial height in males $(r=0.19)$ and females $(r=0.14)$ of central Indian population that it was lower than result of this study. This variance could be affected by climatic, geographic or ethnic difference. ${ }^{32}$

In addition, this study showed that the prediction of facial width for stature estimation is more reliable than facial height among Iranian medical students, whereas the anthropometric features are affected by elements such as different races, nutrition, genetic and geographical situation, ${ }^{33}$ the regression models of the stature from other parts of body can be different in the various regions. Also the correlation between facial indices and stature can be useful in identifying nasofacial dysmorphology, maxillofacial and facial reconstruction surgeries, stature estimation, and the application of forensic. Hence, further studies in different races are required to estimate the stature.

\section{Acknowledgment}

We would like to thank the medical students who participated in this study.

\section{Conflicts of Interest}

The authors declare no conflicts of interest.

\section{References}

1. Oladipo G, Didia BC, Okoh PD, Hart JS. Sexual dimorphism in facial, nasal, maxillary, mandibular and oro-facial heights of adult ljaws. J Exp Clin Anat. 2008:7:10-18

2. Gabriel O, Fawehinmi HB, Peter O. Canthal indices of Urhobo and Itsekiri ethnic groups. Aust J Basic Appl Sci. 2009;3:3093-3096.

3. Golalipour MJ, Hosseinpour KR. Estimation of the cranial capacity and brain weight of Iranian female newborns. Eur J Anat. 2006:10:49-52.

4. Sakakibara H, Tong M, Matsushita K, Hirata M, Konishi Y, Suetsugu S. Cephalometric abnormalities in non-obese and obese patients with obstructive sleep apnoea. Eur Respir J. 1999;13:403-410.

5. Will MJ, Ester MS, Ramirez SG, Tiner BD, McAnear JT, Epstein L. Comparison of cephalometric analysis with ethnicity in obstructive sleep apnea syndrome. Sleep 1995;18:873-875.

6. Martin R, Saller K. Lehrbuch der Anthropologie, Gustav Fisher Verkag. Stuttgart I, 1957, p. 429-547.

7. Kurnia C, Susiana S, Husin W. Facial indices in chinese ethnic students aged 20-22. J Dent Indonesia 2013;19:1-4.

8. Bolzan Gde P, Souza JA, Boton Lde M, Silva AM, Corrêa EC. Facial type and head posture of nasal and mouth-breathing children. J Soc Bras Fonoaudiol. 2011;23:315-320.

9. Doni PKR, Janaki CS, Vijayaraghavan V, Delhi Raj U. A study on measurement and correlation of cephalic and facial indices in males of South Indian population. Int J Med Res Health Sci. 2013;2:439-446.

10. Mohanty BB, Agrawal D, Mishra K, Samantsinghar P, Chinara PK. Estimation of height of an individual from forearm length on the population of Eastern India. J Med Allied Sci. 2013;3:72-75.

11. Singh S, Nair SK, Anjankar V, Bankwar V, Satpathy DK, Malik Y. Regression equation for estimation of femur length in central Indians from inter-trochanteric crest. J Indian Acad Forensic Med. 2013;35:223-226

12. Gocha TP, Vercellotti G, McCormick LE, Van Deest TL. Formulae for estimating skeletal height in modern south-east Asians. J Forensic Sci. 2013;58:1279-1283.

13. Hepper NG, Black LF, Fowler WS. Relationships of lung volume to height and arm span in normal subjects and in patients with spinal deformity. Am Rev Respir Dis. 1965;91:356-362.

14. Saoemes R, Williams P, Bannister L, Berry M, Collins P, Dyson M, et al. Gray's anatomy. In Skeletal System. Churchill Livingstone, Edinburgh, London, 1999 p. 555-560.

15. Jit I, Singh S. Estimation of stature from clavicles. Indian J Med Res. 1956;44:137-155.

16. Shah S, Koirala S, Khanal L. Variations in craniofacial anthropometry in 17-25 year-old adult population of Nepal. Eur J Forensic Sci. 2014;1:5-8.

17. Shetti VR, Pai SR, Sneha G, Gupta C, Chethan P. Study of prosopic (facial) index of Indian and Malaysian students. Int. J. Morphol. 2011;29:1018-1021.

18. Kumar M, Muzzafar Lone M. The study of facial index among Haryanvi adults. Int J Sci Res. 2013;2:51-53.

19. Wai MM, Thwin SS, Yesmin T, Ahmad A, Adnan AS, Hassan AA, et al. Nasofacial anthropometric study among university students of three races in Malaysia. Adv Anat. 2015;2015:5.

20. Sharma K, Khanal K, Mansur DI. Variations in total facial index among students of Kathmandu University School of Medical Sciences. Nepal Med Coll J. 2014;16:173-176.

21. Azizi M, Hassanzadeh G, Barbarestani M, Sadr M, Dehbashipour A, Alaghbandha $\mathrm{N}$, et al. Comparative anthropometric analysis of facial dimensions and types in Qazvin, Iran and DeraGhazi Khan, Pakistan. Anat Sci J. 2014;11:119-126.

22. Jahanshahi M, Golalipour MJ, Heidari K. The effect of ethnicity on facial anthropometry in Northern Iran. Singapore Med J. 2008:49:940-943.

23. Salve VM, Thota NR, Naralasetty A. Study of facial (prosopic) index of Andhra Region (India) Students. Novel Sci Int J Med Sci. 2012;1:248-252.

24. Krishan K. Estimation of stature from cephalo-facial anthropometry in north Indian population. Forensic Sci Int. 2008;181:52.e1-52.e6.

25. Balvir TK, Deshpande JV, Badwaik P, Rahule AS, Kasote AP, Bashir MSM, et al. Estimation of stature from the lenth of clavicle in vidarbha region of maharashtra. Int J Biol Med Res. 2012;3:2254-2256.

26. Moshkdanian G, Mahaki Zadeh S, Moghani Ghoroghi F, Mokhtari T, Hassanzadeh G. Estimation of stature from the anthropometric measurement of lower limb in Iranian adults. Anat Sci J. 2014;11:149-154.

27. Poorhassan M, Mokhtari T, Navid S, Rezaei M, Sheikhazadi A, Mojaverrostami S. Stature estimation from forearm length: an anthropological study in Iranian medical students. J Contemp Med Sci. 2017;3:270-272.

28. Mahakizadeh S, Moghani-Ghoroghi F, Moshkdanian G, Mokhtari T, Hassanzadeh G. The determination of correlation between stature and upper limb and hand measurements in Iranian adults. Forensic Sci Int. 2016;260:27-30.

29. Krishan K, Kumar R. Determination of stature from cephalo-facial dimensions in a North Indian population. Leg Med (Tokyo). 2007;9:128-133. 
30. Sahni D, Sharma P, Kaur G, Aggarwal A. Estimation of stature from facial measurements in northwest Indians. Legal Medicine. 2010;12:23-7.

31. Agnihotri AK, Kachhwaha S, Googoolye K, Allock A. Estimation of stature from cephalo-facial dimensions by regression analysis in Indo-Mauritian population. J Forensic Leg Med. 2011;18:167-172.
32. Wankhede KP, Kamdi NY, Parchand MP, Anjankar VP, Bardale RV. Estimation of stature from maxillo-facial anthropometry in a central Indian population. J Forensic Dent Sci. 2012;4:34-37.

33. Akhlaghi M, Hajibeygi M, Zamani N, Moradi B. Estimation of stature from upper limb anthropometry in Iranian population. J Forensic Leg Med. 2012;19:280-284.

This work is licensed under a Creative Commons Attribution-NonCommercial 3.0 Unported License which allows users to read, copy, distribute and make derivative works for non-commercial purposes from the material, as long as the author of the original work is cited properly. 